\title{
The combined process of PAC-MBR on wastewater treatment
}

\author{
Jun Yang 1, 2,a, Yongwei Song ${ }^{1,2, b}$, Jingdong Zhang ${ }^{1,2, c}$ \\ ${ }^{1}$ Institute of Environmental Management \& Policy, Zhongnan University of Economics and Law, \\ Wuhan 430073, China; \\ ${ }^{2}$ Research Center for Environment \& Health, Zhongnan University of Economics and Law, Wuhan \\ 430073, China.

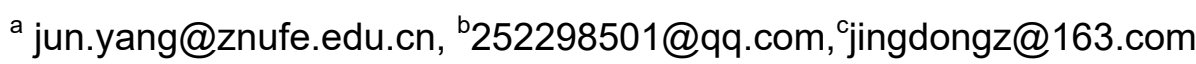

Keywords: MBR, PAC, water treatment, membrane fouling

\begin{abstract}
Membrane bioreactor (MBR) technology has currently been widely researched and used in water treatment field. In order to further expand the application fields and control membrane fouling problem of MBR, powdered activated carbon-membrane bioreactor (PAC-MBR) combined technology has become a study hotspot in MBR technological fields. On the basis of introducing the principle of PAC-MBR combination process, the impact of PAC dosing on the key operation parameters and membrane fouling of this process is detailed discussed. Finally, the application status of this combined technology in water treatment field is introduced, and the research and application prospect is forecasted.
\end{abstract}

\section{Introduction}

The study reports on MBR have begun to appear since the 1970s. In the 1990s, the technology was researched widely and developed rapidly. However, membrane fouling problem has been hindering the study, application and promotion of MBR.

Membrane fouling is the major bottleneck currently that restricts MBR wide application. And it resulted in the membrane flux decreasing and the frequency of membrane components replacement and cleaning increasing, and system aeration energy consumption increasing, thus increasing running cost of MBR. Therefore, one of the core questions of MBR stability operation is controlling membrane fouling. The key and difficult point in the field is researching the countermeasure of delaying membrane fouling $[1,2]$.

In order to control membrane fouling effectively and expand the application area of MBR further, in recent years, all kinds of combination process arise, such as MBR-ultrasonic combination process, MBR-light catalyzing combination process, MBR-ozone oxidation process, MBR-compound coagulant combination process, hydrolysis/aerobic MBR combination process, PAC-MBR combination process and so on.

Many researchers put PAC into MBR to study its effect on membrane fouling and the effluent quality. Numerous studies show that biological activated carbon (BAC) sludge that formed after adding PAC can greatly improve the characters of mixed liquor, and it not only can reduce the content of dissolved and colloidal substances, control membrane fouling in the smallest range, improve the membrane flux, and can improve effluent quality.

\section{Principle and operation of PAC-MBR combination process}

\subsection{Principle of PAC-MBR combination process}

PAC-MBR combination process that put PAC in MBR sludge mixed liquor and the sludge floes surround PAC particles, and adsorpt and flocculate EPS, subtle colloid, soluble organic matter in sludge mixed liquor, which can largen the diameter of sludge particles, strengthen compressive ability, improve membrane surface sediments of porosity, and reduce the compaction, thus reduce resistance of membrane filtration and membrane pollution degree, and enhance the flux. 
At the same time, because the adsorption of PAC sludge floes and biodegradable is synergistic [3, 4], biological activated carbon is formed and removal efficiency of organic contaminant is improved, and PAC regenerates.

Moreover, most researchers believe that because the interception effect of membrane and adsorption and carrier function of PAC sludge floes improve the content and activity of nitrifying bacteria, which reduces the content of ammonia nitrogen of reactor. In addition, removal efficiency of polluted factors (such as turbidity and so on) is improved, because the performance of sludge mixed liquor has been improved.

\subsection{PAC-MBR combination process operation}

Compared with traditional activated sludge membrane bioreactor (AS-the MBR), PAC-MBR combination process is adjusted including aeration rate, flux, transmembrane pressure differential and membrane washing cycle, etc. The right PAC dosing quantity directly related to the membrane pollution condition and effluent quality and it is the key to determine stable operation of process.

\subsubsection{PAC dosage}

The PAC dosing quantity relates to components, size and intensity of the mixture sludge whether can help reduce the membrane pollution state. Too little PAC dosing quantity can make effect unconspicuous; too much dosing quantity, due to excessive speed of adsorption PAC, adsorption effect may compete with biodegradable effect. PAC priority adsorptes small molecules that easily degraded, so that difficult biodegradable material in the reactor increases, and lead to self decomposition of microbial becomes faster and faster, produce more EPS, thus increase the biological pollution [5]

Through the experiments, Wang GD [6] obtained that put about $1 \mathrm{~g} / \mathrm{L}$ PAC in MBR system can reduce the membrane pollution, improve water quality and running effect is good. Other researchers' reports also confirmed the conclusion.

\subsubsection{Aeration rate}

At present, the main reason that limits popularization and application of the MBR technology is high operation cost because to maintain high membrane flux should use big aeration rate.

The improved PAC-MBR combination process has good effluent quality, and because of interaction of PAC and active sludge slow down adsorption of the small molecules in the film and jams in film hole, and improve the membrane surface sediments structure and properties, thus make MBR can maintain low resistance in membrane filtration and high membrane flux long time under the condition of the lower gas water ratio, and greatly reduce the energy consumption. It has great practical significance to popularization and application of the MBR process.

\subsubsection{Critical flux and transmembrane pressure}

The illuvial horizon that formed biological activated sludge that formed after putting PAC in the membrane surface is porous loose, and resistance to compression ability is enhanced, membrane filtration pressure rising rate reduces significantly, and critical flux rises.

Li, Y. Z. [9] compared membrane filtration properties of the biological activated carbon membrane biological reaction system (BAC-SMBR) and conventional activated sludge membrane biological reaction system (AS-SMBR) in the same feed water and running condition, and the results show that, compared with AS-SMBR BAC-SMBR critical flux can improve $32 \%$. Long-term operation results in the same permanent flux also show that BAC-SMBR membrane pressure increase became much more slowly. Guo, W. S. [15] pointed out that dosing PAC can make the MBR system in lower transmembrane pressure differentials maintain higher flux. Satyawali, Y. [16] in the study of PAC-MBR technology treatment fermentation wastewater proved that dosing PAC can promote critical flux about 23\%. Remy, M. [17] also proved that putting a few $\mathrm{PAC}$ in MBR can make the system operate for a long time in higher flux.

\subsubsection{Membrane cleaning frequency and way}

During MBR operation, membrane fouling after a period of slow growth and transmembrane pressure sharply rise and flux lowers. At this time, to reduce the transmembrane pressure differential must through the membrane cleaning, and restore flux. Film cleaning methods include physics cleaning and chemical cleaning. 
Because PAC adsorptes and degradates matter that cause the membrane pollution, especially small molecules, thus ease membrane pore blocking. At the same time, the sludge floes sorround PAC particles formed loose illuvial horizon in the membrane surface can effectively intercept pollution material near the membrane surface, and protect the membrane module, which will greatly reduce the difficulty of cleaning. We can regain flux by physics clean only, so as to reduce usage of chemicals, and extend the membrane cleaning cycle and useful life [18-20].

Contrast experiment of PAC-MBR and MBR sewage treatment process by Li, S. F. [21] shows that, because of the existence of PAC, has greatly improved the membrane fouling condition, thus extends membrane washing cycle. The parallel experiment by Li, Y. Z. [9], Lin, G. J. [22] proved that dosing PAC can effectively slow membrane fouling of membrane bioreactor, and the last time of membrane fouling development stages extended 1-2 times.

\subsection{PAC-MBR combination process special variant.}

Based on some special processing requirements, the researchers changed PAC-MBR combination process, in order to obtain high flux, high removal efficiency or more stable performance.

Wang, W. [23] and Wei, J. F. [24] combined powder activated carbon PAC process with dynamic bioreactor (DMBR), and applied to treat sewage, achieved better treatment effect than single DMBR.

Zhang, H. M. [25] used PAC as precoating reagent and industrial filter cloth membrane modules to make up pre-coating dynamic membrane bioreacto. Not only remove effect of pollute material is better, but also pre-coating film can prevent pollution and microbial material diffusion to membrane surface and internal, and reduce the membrane fouling, membrane flux can be restored by scrubbing, that does not need to consume chemical reagent. In his another study, he used biological ceramic column and powder active carbon with membrane bioreactor, made up the biological ceramic column PAC-MBR system to treat drinking water. It not only solved the weakness that membrane bioreactor remove ammonia nitrogen and avoid accumulation of nitrite, and greatly reduced the membrane bioreactor organic load, and average removal rate of permanganate index is $76.97 \%$, average removal rate of ammonia nitrogen and nitrite are $95.50 \%$ and $99.15 \%$ respectively. This process can also reduce concentration polarization, delay membrane fouling, sum film hole resistance and filter cake resistance in the process of the test down $72 \%$ than single membrane bioreactor.

Ye, M. S. [26] pre-coated PAC on ordinary polyester filter cloth surface, formed pre-coating dynamic membrane instead of traditional micro filter ultrafiltration membrane, and construct pre-coating dynamic membrane bioreactor. Operation for one month, COD removal rate was 97.5\% water, ammonia nitrogen removal rate was $76.1 \%$, and membrane filtration pressure rose to 0.27 Mpa. The result of experiment showed that the PAC pre-coating dynamic membrane technology can significantly improve the system stability.

\section{PAC- MBR combination process membrane fouling}

Membrane fouling is because the main components and the liquid membrane interaction, the film hole jams the membrane surface sediments and pollutants, which led to the formation of the flux of membrane, reduced quickly across the sharp increase of pressure difference phenomenon. Membrane pollution essence is the membrane surface and film hole of pollutants, and sources of air pollutants is activated sludge, therefore, control the mixture activated sludge mixture character is a important and feasible way [27, 28].

Compared with the traditional MBR, PAC-the MBR because of activated carbon powder and improve the sludge to join the mixture character, make the mixture to filter performance improved, membrane pollution rate. PAC to film the effects of the pollution of the main performance to improve the sludge was particle size distribution, strengthen body sludge was resistance body compression capacity; reduce the mixture to extracellular polymer (EPS), subtle colloid, solubility pollutants concentration [29-31]. 


\subsection{Influence of additive PAC to particle size of sludge floe and compression performance}

The sludge diffusion coefficient decreases with increasing the particle diameters. In theory, when the particle diameter is more than $1 \mu \mathrm{m}$, shearing force of spreading has priority, membrane surface particles affected by shear force strongly. Thus, the sludge particles size has close relationship with filter resistance. Relative to the large particle size particles, small size particles can cause more serious membrane fouling. In the beginning of the filter, particulate smaller than the membrane pore block, fine particles which bigger than pore size and smaller than $1 \mu \mathrm{m}$ deposited on the surface membrane $[30,32]$

Size of activated sludge in PAC-MBR is a little large, activated carbon powder particles are surrounded with active sludge in mixed liquor so that form many micro flocculent grains, several micro flocculent grains that in the center of PAC form a larger flocculent. Adsorption and adhesion of the internal flocculant grain is strong, so it can resist the shearing action of strong aeration on a certain extent. It's not easy to be broken, and it can exist stably in main body of liquid [7, 23, 27, 33]. Simulated sewage as object, Zhu, Y. S. studied influence of PAC on MBR membrane fouling and found that average particle size of sludge in reactor that put PAC is higher 1.5 times than the reactor without PAC [7]. In the same operation condition Yang, W. [34] compared sludge flocs size distribution in singular MBR and PAC-MBR, found that after putting PAC, average particle size of sludge flocs increase more than $20 \%$.than the size in MBR

In PAC-MBR system, the sludge flocs surround one or several PAC particles to form larger particles. As activated carbon in the flocs plays the role of center, it increases flocs resistence and the porosity of membrane surface sediments, and reduces membrane filter resistance, and improves critical flux $[8,23,27,30]$.

\subsection{Influence of additive PAC to EPS content and viscosity}

Extracellular polymer (EPS) is microorganismin active sludge in certain circumstances; it is mainly bacterial metabolites secreted by cells or cell autolysis material. A lot of researches showed that EPS is priority pollutants of MBR membrane fouling. Gel layer that formed by soluble substances and subtle colloid, EPS, etc in the membrane surface is the main pollutants film outside.

Cao, X. X. [30] studied and found that additive PAC can significantly reduce the soluble substances concentration and viscosity of mixed liquor, and reduce adsorption of the dissolved pollutants and pore clogging pollution.

Yang, W. [34] etc through experiments of the MBR and PAC- MBR process proved EPS have big relevance with membrane fouling, and because PAC has strong adsorption and flocculation effect, it can reduce EPS content and viscosityof the sludge mixture. Other researchers also confirmed the above conclusion [1, 29, 35].

Ying, Z. [36] points out that loose sediments formed in the membrane surface after putting PAC can stop EPS, colloid pollution material close to the membrane surface, and slow the membrane surface fuling. In addition, Kim [37] thinks the reason of decrease of EPS content in PAC-MBR system may be apparent differences between sludge flocculent of microbes physiological characteristics and the traditional MBR of activated sludge, so that produce the amount of EPS reduced. Satyawali, Y. [38] points out in the alcohol wastewater research, putting PAC can improve EPS protein and carbohydrates $(\mathrm{P} / \mathrm{C})$ ratio of sludge mixture, thus improve hydrophobic performance of sludge, reduce adhesion between sludge and Membrane hydrophilic, improve membrane pollution condition

\section{Application fields of PAC-MBR combination process}

Researches on MBR technology have been focused on the city and life sewage treatment in China since late nineties. In recent years, about the research of MBR and application object has been gradually developed to the refractory industry waste water and high strength waste water, and application field is increasingly widespread.

\subsection{Municipal and domestic sewage}

Research reports on MBR process used in city and life sewage treatment are the most; many researchers agree that additive PAC has significant inhibitory effect on membrane fouling. However, 
about the influence to pollutant removal efficiency after putting PAC, different researchers have different opinions.

Many researchers such as Whang, G. D. etc [6, 8, 10, 22, 23] think additive PAC can improve organic pollutant removal efficiency. In PAC-MBR combination process reactor, additive PAC can form biological activated carbon (BAC), which causes the synergy effect of adsorption and biodegradation. The existence of PAC increases the solid and liquid contact area, microbial cells, enzymes, organic matter and oxygen that adsorpt on activated carbon surface to provide a good environment for microbial metabolism. Microbial enzymes can enter the microporous of activated carbon, thus degradate organic matter that adsorpted, and empty out adsorption potential to make active carbon biological regeneration, and increase carbon adsorption ability greatly, to some extent, improve the organic pollutant removal efficiency [39, 40].

Xie, F. B. [41] analyzed by the experiment results, because PAC sludge floc particles was a little big, it's easy to form aerobic and anoxic environment; In addition, nitrifying bacteria mainly grows by adsorption state, PAC floc sludge can adsorpt nitrifying bacteria and become the good vehicle of nitrifying bacteria growth, so as to improve the content and activity of nitrifying bacteria, and improve the ammonia nitrogen removal efficiency.

However, Lin, H. J. [22] pointed out that additive PAC can improve removal efficiency of the organic pollutants, but removal impact to ammonia nitrogen and turbidity is not big.

Some researchers think additive PAC can't significantly improve water quality. Wang, X. Q. [29] thinks, using PAC- MBR process to remove pollutants has many advantages in the early stage, but with the extension of time, the active carbon adsorption ability is abate, the advantages of the technology is reduced. Zhu, Y. S. [7] proved by experiments effect that improved water qualities not apparent by additive PAC. No matter whether putting PAC, total removal efficiency of COD and ammonia nitrogen always achieve above $95 \%$, the removal of pollutant mainly rely on biological function.

\subsection{Micro-polluted surface water}

Micro-polluted water means drinking water source is polluted by organic matter, some index is above health index. Huge amount of water, low pollutant content low, and the variety of pollutants is various, especially some difficult degradable, easy to biological accumulation and poisonous and harmful contaminants. Therefore, how to deal with micro-polluted water economically and effectively has plagued the related research and management departments.

At present, many researchers have been studying PAC-MBR combination process. Li, S. F. [42] applied MBR system and PAC-MBR system respectively to treat disrupting chemicals atrazine. The results showed that the removal rate of atrazine reached $54.16 \%$ in the PAC-MBR system, much higher than the removal rate of $20.22 \%$ of the MBR system. In addition, the microorganism quantity in the PAC-MBR system was almost two orders of magnitude than a typical MBR, and has better anti-shock Loading Performance. Ravindran, V. [43] concludes that the removal rate of PAC-MBR is $50 \%$ higher than a single MBR through a contrast experiment.

Chen, Y. L. [44], Tian, J. Y. [45] applied the PAC-MBR combination process to treat micro-polluted surface water. It is proved by experiments that PAC can not only slow membrane pollution, and has the obvious remove effect on the small molecules pollutants $(\mathrm{mw}<3000)$ to the MBR reactor. Sun, X. [46], Xu, G. X. [47] also add PAC in MBR process to treat micro-polluted surface water, and the result shows that it has notable effects on the removal of CODMn, ammonia nitrogen and turbidity, and the process don't need additional coagulant, reduce the amount of chlorine at the same time. It can not only save costs but also reduce the harmful material in surface water to the human body.

\section{3 coking wastewater}

The production and consumption of coke are very high in China. The amount of coking wastewater's production is large, and composition is complicated. Furthermore, according to the coal quality, production process, the water quality of the coking enterprises has a big difference.

Through summarization the latest progress and development of the coking wastewater treatment technology of different process, Huang, L. Q. [48] points out that the reasonable combination of 
different processes is one of the development directions for the coking wastewater treatment, and introduced the PAC-MBR combination technology for coking wastewater treatment.

Pei, L. [49] studied pollutant removal efficiency that used PAC-MBR combination process to treat coking wastewater. The results showed that, compared with MBR process, combination process on the removal rate of COD increased by about $25 \%$. It explained that PAC adsorption can significantly improve organic removal rate of the MBR system. When water temperature is more than $22^{\circ} \mathrm{C}$, pH7 $\sim 8$, DO is more than $3 \mathrm{mg} / \mathrm{L}$, ammonia nitrogen removal efficiency by combination process is higher than $98 \%$; Turbidity removal rate of the two processes differs little. It explained that the turbidity removal is mainly interception of function through the membrane, additive PAC can't significantly improve turbidity removal rate of MBR.

Li, C. J. [50] studied membrane pollution effect that used SMSSBR process to treat coking wastewater. After adding powder activated carbon (PAC) into reactor, biological activated carbon (BAC) is formed, sludge sediments resistance is reduced and membrane pollution rate is slowed.

\subsection{Printing and dyeing wastewater}

For a long time, printing and dyeing wastewater because of its large water volume, high organic pollutant content, deep chromaticity, big alkaline water quality change and other characteristics, has been one of industrial wastewater that difficult to deal with. Along with the development of processing technology and application of new dyes and fertilizer, the difficulty of dealing with the printing and dyeing wastewater has being increased.

Hai, F. I. [51]compared the effect of treating mixed azo dye wastewater among activated sludge method, active sludge-membrane bioreactor (AS-the MBR) and PAC- MBR process, the results showed that membrane sediments have very good adsorption and degradation effect to dye molecules. After putting PAC, the removal rate of chrominance and TOC is above $99 \%$, and their enzyme activity can be maintained high level.

\subsection{Landfill leachate}

In recent years, MBR researches and applications our country have been gradually developed to the bio-refractory organic pollutants and high concentration organic industry water from the municipal sewage, and its application field is increasingly widespread. Landfill leachate was the representative wastewater for its bio-refractory and high concentration. Many researchers combined MBR technology and PAC adsorption technology to treat landfill leachate, and obtained good results.

Xie, X. H. [52] compared the ammonia nitrogen removal efficiency of MBR and PAC-MBR in landfill leachate treatment, and the study found that the both processes could only change ammonia nitrogen into $\mathrm{NO}_{2}^{-}$under the conditions of hydraulic retention time in $3 \mathrm{~d}$, ammonia nitrogen 200 $-500 \mathrm{mg} / \mathrm{L}$ and water $\mathrm{pH}>8.7$. However, when the $\mathrm{pH}$ was decreased to 7.6-8.2, the activity of nitrite oxidation bacteria is quickly recover in PAC-MBR, and transform $\mathrm{NO}_{2}^{-}$into nitrate completely, but ordinary MBR still stay on Nitrification stage.

Liang, J. B. [53] applied PAC-MBR combination technology treating landfill leachate, and it could achieve favorable treatment effects in a short term. The removal rates of COD, BOD and ammonia nitrogen can reach $72 \%, 85 \%$, and $72 \%$ respective.

\section{Summary and prospect}

The research on PAC-MBR combination process has been exceeded 20 years. Some common understandings are formed: generally speaking, the best PAC dosage is $1 \mathrm{~g} / \mathrm{L}$; then the PAC is becoming the framework of the flocs which adsorb EPS, subtle colloid, soluble organic compounds; it is followed by the growth of particle size, strengthen of stress resistance, increasing of porosity of membrane surface sediments, improved filter and settlement performance, which can reduce the resistance in membrane filtration and membrane pollution degree, enhancing the flux.

At the same time, because of adding PAC and the formation of biological activated carbon, which causes the coordination effect of the adsorption and biodegradation of organic matter, the adsorption and degradation effect of microorganism and the renew of activated carbon in the whole 
flocculent body take place simultaneously and maintain a dynamic balance, which extend the PAC adsorption capacity, improve the content and activity of nitrifying bacteria, and thus increase the removal efficiency to a certain extent, ensure stable quality of effluent water.

In PAC-MBR combination process, the adsorption-degradation collaborative mechanism and EPS change mechanism are to be further research. In addition, in order to get a more effective treatment effect, and to broaden the applications fields of this combination process. Different operation parameters aiming at treating high concentration, difficult degradable and some special industry wastewater should be studied in-depth. At present, the micro-polluted surface water PAC-MBR treatment technology is developed rapidly, the PAC-MBR combination process will be a competitive technology in this field.

\section{Acknowledgements}

This work was supported by the China Postdoctoral Science Foundation (2015M582316).

\section{References}

[1] Xia, J. Master Degree Thesis. 2008.

[2] Huang, X.; Cao, B.; Wen, X. H. Journal of Environment Science, 2008, 28, 416-432.

[3] Zhang, L. Q,; Urase, T.; Feng, L. 2008, 199-205.

[4] Lesage, N.; Sperandio, M.; Cabassud, C. Chemical Engineering and Processing, 2008, 47, 303-307.

[5] Zhao, Y.; Yu, D. D.; Qin, D. P. Water Science and Technology. 2005, 33, 52-55.

[6] Whang, G. D.; Cho, Y. M.; Park, H. Water Science and Technology. 2004, 49, 451-457.

[7] Zhu, Y. S. Master Degree Thesis. 2009.

[8] Zhang, F. J.; Wang, S. Y.; Liu, T. Journal of Jilin University. 2007, 37, 350-354.

[9] Li, Y. Z.; He, Y. L.; Liu, Y. H. Water supply and drainage. 2004, 20, 11-13.

[10] Pei, L.; Yao, B. H. Environment Engineering, 2008, 26, 7-9.

[11] Li, J.; Jiang, D. G.; Song, W. H. Journal of Beijing University of Technology. 2006, 32, 1022-1027.

[12] Luo, H.; Gu, P.; Yang, Z. Y. Chongqing Environment Science. 2002, 24, 28-31.

[13] Zheng, S. P.; Sun, L. P. Journal of Tianjin institute of urban Construction. 2004, 10, 191-193.

[14] Dosoretz, C. G.; Boddeker, K. W. Journal of Membrane Science. 2004, 239, 81-90.

[15] Guo, W.S.; Vigneswaran, S.; Ngo HH, et al. Desalination. 2008, 231, 61-70.

[16] Satyawali, Y.; Balakrishnan, M. Journal of Hazardous Materials. 2009, 170, 457-465.

[17] Remy, M.; van der Marel, P.; Zwijnenburg, A. Water Research. 2009, 43, 345-350.

[18] Hao, A. L.; Chen, Y. L.; Gu, P. Membrane Science and Technology. 2007, 27, 35-40.

[19] Sun, X.; Sun, J.; Zhang, D. H. Environment pollution processing and equipment. 2006, 7, 89-91.

[20] Yang, W.; Paetkau, M.; Cicek, N. Water Science and Technology. 2010, 62, 172-179.

[21] Li, S. F.; Wang, X. Q.; Wang, H. J. Water Treatment Technology. 2007, 33, 14-17.

[22] Lin, H. J.; Lu, X. F.; Wang, W. L. Journal of Shanghai University of Science Technology. 2007, 29, 154-158. 
[23] Wang, W.; Yang, C. Z.; Pu, W. H. Environment Science and Technology. 2007, 30, 64-65.

[24] Wei, Q, F.; Zhang, H. M.; Ye, M. S. Water supply and drainage of China. 2007, 23, 48-52.

[25] Zhang, H. M.; Qiao, S.; Ye, M. S. Journal of Environment Science. 2005, 25, 249-253.

[26] Ye, M. S.; Zhang, H. M.; Yang, F. L. Desalination. 2008, 230, 100-112.

[27] Li, Y. Z.; He, Y. L.; Liu, Y. H. Environment Science Technology. 2005, 18, 52-55.

[28] Chang, I. S.; Le, C. P.; Jefferson, B. Journal of Environmental Engineering-asce. 2002, 128, 1018-1029.

[29] Wang, X. Q. Master Degree Thesis. 2006.

[30] Cao, X. X.; Wei, C. H.; Huang, X. Journal of environment science. 2005, 25, 1443-1447.

[31] Seo, G. T.; Jang, S. W.; Lee, S. H, et al. Water Science and Technology. 2005, 51, 77-84.

[32] Cao, Z. P.; Zhang, J. L.; Zhang, H. W. Chemical Process. 2008, 27, 1429-1434.

[33] Remy, M.; Potier, V.; Temmink, H. Water Research. 2010, 44, 861-867.

[34] Yang, W.; Paetkau, M.; Cicek, N. Water Science and Technology. 2010, 61, 2193-2198.

[35] Lee, W. N.; Yeon, K. M.; Hwang, B. K. Separation Science and Technology. 2010, 45, 896-903.

[36] Ying, Z.; Ping, G. Separation and Purification Technology. 2006, 52, 154-160.

[37] Kim, J. S.; Lee, C. H.; Chun, H. D. Water Research. 1998, 32, 3443-3451.

[38] Satyawali, Y.; Balakrishnan, M. Water Research. 2009, 43, 1577-1588.

[39] Lesage, N.; Sperandio, M.; Cabassud, C. Water Science and Technology. 2005, 51, 173-180.

[40] Omer, S.; Yaxi, S.; Ailing, H. Separation Science and Technology. 2008, 58, 320-327.

[41] Xie, F. B.; Mai, W. N.; Yang, Z. Chemical Process. 2008, 27, 791-794.

[42] Li, S. F.; Qin, J. J.; Chen, L. Water Treatment Technology. 2009, 35, 52-55.

[43] Ravindran, V.; Tsai, H. H.; Williams, M. D, et al. Journal of Membrane Science. 2009, 344, 39-54.

[44] Chen, Y. L.; Zhang, Y.; Hao, A. L. Chinese Public Health. 2005, 21, 1474-1476.

[45] Tian, J. Y.; Liang, H.; Yang, Y. L. Journal of Membrane Science. 2008, 325, 8.

[46] Sun, X.; Xu, G. X.; Zhu, Y. B. Water supply and drainage. 2005, 31, 35-38.

[47] Xu, G. X.; Pan, S. K.; Xu, G. R. Water supply and drainage of China. 2005, 21, 43-45.

[48] Huang, L. Q. Water Treatment Technology. 2008, 34, 1-6.

[49] Pei, L.; Dong, B.; Yao, B. H. Water supply and drainage of China. 2007, 23, 60-62.

[50] Li, C. J.; Geng, Y.; Zhou, Q. Water supply and drainage. 2002, 18, 5-9.

[51] Hai, F. I.; Yamamoto, K.; Nakajima, F, et al. Journal of Membrane Science. 2008, 325, 395-403.

[52] Xie, X. H.; Wu, C. Q.; Guo, S. H. Environment pollution processing and equipment. 2006, 7, $75-78$.

[53] Liang, J. B.; Yang, K.; Zhang, D. Y. Environment Science and Technology. 2006, 29, 93-94. 